\title{
EU to review rare disease drugs market exclusivity
}

Biotech companies that base their business strategy on orphan drug development are bracing themselves for a European Commission (EC) report on orphan drug pricing. EC officials are finalizing a study this month on the relationship between profitability and market exclusivity provisions, focused on the first eleven approved orphan drugs allowed in the European Union. Industry observers fear that, by 2006, the EC will tighten the legislation by reducing market exclusivity.

A 10-year market exclusivity remains the main carrot to entice companies to develop new drugs against rare disease; 'orphan drug' status is given either because of the low prevalence (below a threshold of five in 10,000 across the EU) of the disease the drug is targeting or because the drug would otherwise not offer a return on investment. But article 8 of the EU's orphan drug regulation $(141 / 2000)$, in force since 2000 , allows for the reduction of a product's market exclusivity period to six years if, after five years, the drug is deemed "sufficiently profitable" and no longer entitled to its exclusivity status.

The term "sufficiently profitable" in the legislation, however, has remained undefined. The current study, conducted by Alcimed, a consultancy based in Paris, will help the EC to develop a general method for assessing the profitability of orphan products before May 2006; by then, the first two products to receive orphan approval in the EU will have been on the market for five years. These are Fabry disease treatments Fabrazyme and Replagal, developed, respectively, by Genzyme and Transkaryotic Therapies, both of Cambridge, Massachusetts (Nat. Biotechnol. 19, 802, 2001). "We hope to reach quite a simple solution that would be applicable to everything," says Patrick Accart, an official at the pharmaceuticals unit of the Brussels-based EC's directorate general for enterprise.

Which products should be assessed is an issue under debate. Fabrizia Bignami, therapeutic development officer at Eurordis, a Paris-based coalition of patient groups focused on rare diseases, believes that the EC should restrict its review to "those products which have been designated [as orphans] only on the basis of insufficient return on investment," rather than automatically review all orphan drugs that have been on the market for five years. The Eurordis proposal would result in quite a liberal regime as, so far, all of the EC's 194 orphan drug designations have been made according to prevalence, rather than economic, criteria.

Although subject to the EU legislation, individual member states retain ultimate responsibility not only for determining reimbursement within their respective healthcare systems, but also for initiating a review of orphan drugs in their territory. EU nations are secretive in the way they deal with orphan drugs and accord a level of priority to promoting orphan drugs that varies widely across countries, according to a survey carried out last year by Eurordis. This fragmentation can make negotiations on orphan drug pricing difficult for some national authorities and it also poses significant forecasting and budgeting challenges to biotechs.

The provision of incentives to promote orphan drug research and development suffers from a similar level of fragmentation among the policy of EU countriesthis does not bode well for biotech. The EU's orphan drug system also has the scope for individual member states to put in place additional incentives, such as tax credits and grants for clinical trials. But few, if any, meaningful measures have been implemented so far, according to two successive EC audits. That failure adds weight to industry concerns aroused by the Alcimed study.

In the absence of any other incentives to develop orphan drugs, companies have placed a disproportionate emphasis on the importance of having a ten-year market exclusivity. "If you take that away, you've got nothing at all, and it sends the wrong message out," says Wills Hughes-Wilson, manager of Emerging Biopharmaceutical Enterprises (EBE), a biotech lobby group whose firms collectively account for $35 \%$ of current orphan drug designations.

Although individual companies were unwilling to comment publicly on the report at this stage of the process, any tightening up of the EU market exclusivity perk will deepen the contrast between its fledgling orphan drug regime and that of the United States, which has been in place since 1983. The latter provides just seven years of market exclusivity, but it also offers companies a more comprehensive set of supports, including grants for clinical trials and tax credits that allow them to write off up to half of their clinical development costs. "The success of the US system is demonstrated in just sheer numbers of products coming to the market," Hughes-Wilson says. "In the EU, we've managed to achieve 14 product approvals. In the US, in the same period, [they've achieved] 47.'

"That's a good challenge for us, certainly," says Agnès Saint Raymond, a member of the London-based European Medicines Agency's Committee for Orphan Medicinal Products, which is preparing a contribution to a wider review of the overall functioning of the EU's orphan drug system due to be published in January 2006.

Cormac Sheridan, Dublin

For more news and analysis go to news@nature.com www.nature.com/news 